\title{
Intestinal obstruction due to diffuse peritoneal fibrosis at 2 years after the successful treatment of malignant peritoneal mesothelioma with intraperitoneal mitoxantrone (Short communication)
}

\section{Thomas Vlasveld ${ }^{1}$, Babs G. Taal ${ }^{1}$, Bin B. R. Kroon ${ }^{2}$, Maarten P. W. Gallee ${ }^{3}$, and Sjoerd Rodenhuis ${ }^{1}$}

${ }^{1}$ Department of Medical Oncology, ${ }^{2}$ Department of Surgery, and ${ }^{3}$ Department of Pathology, The Netherlands Cancer Institute, Antoni van Leeuwenhoek Huis, Plesmanlaan 121, 1066 CX Amsterdam, The Netherlands

In: Cancer Chemother Pharmacol 29: $405-408$

On page 406 Fig. 2 was accidentally placed upside down. The figure should have been printed as below.

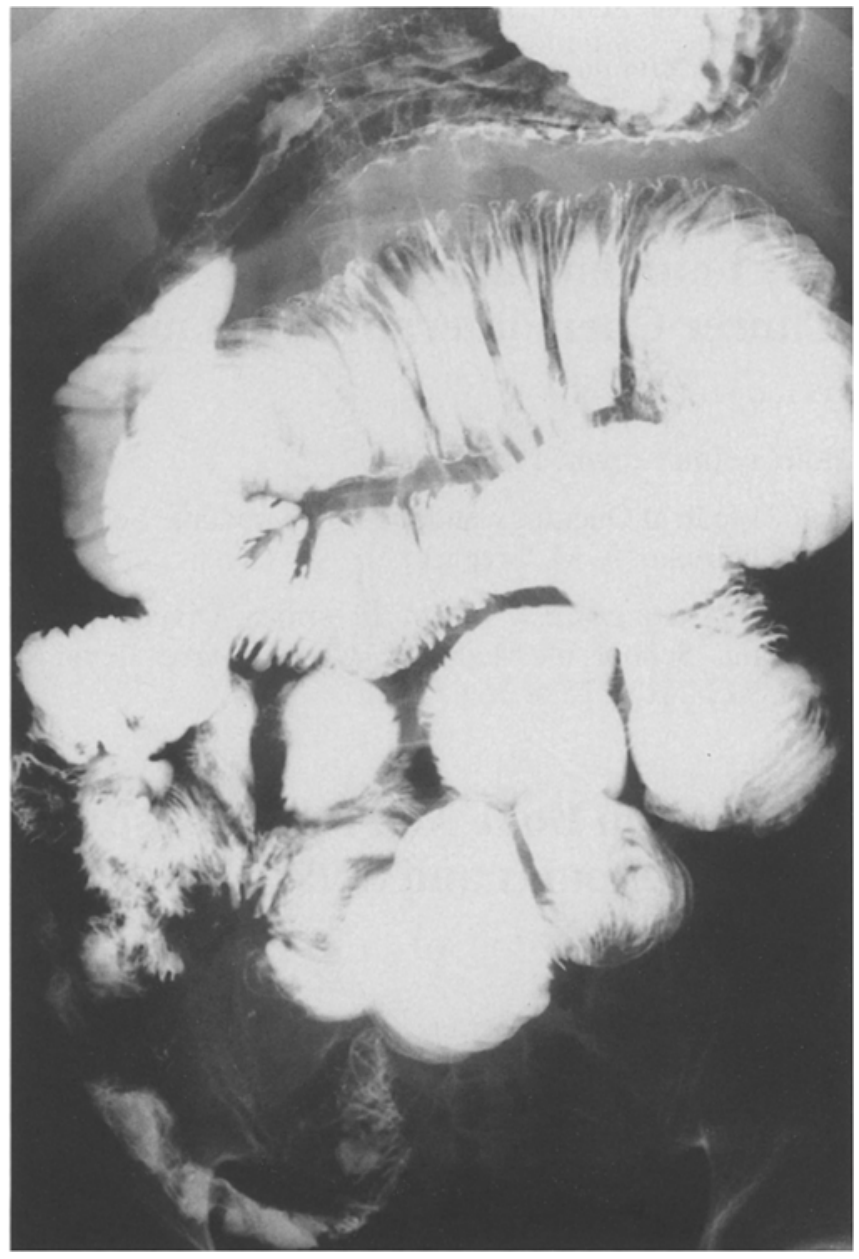

Fig. 2. The upper gastrointestinal series demonstrates rough gastric mucosal folds along with narrowing of the antrum. The small-bowel loops are dilated due to a stenosis in the distal jejunum 